\title{
Living Cationic Homo- and Copolymerizations of Vinyl Ethers Bearing a Perfluoroalkyl Pendant
}

\author{
Won Ok Choi, Mitsuo Sawamoto, and Toshinobu Higashimura* \\ Department of Polymer Chemistry, Faculty of Engineering, \\ Kyoto University, Kyoto 606, Japan
}

(Received July 29, 1987)

\begin{abstract}
Two vinyl ethers with a perfluoroalkyl group, $\mathrm{CH}_{2}=\mathrm{CH}-\mathrm{OCH}_{2} \mathrm{CH}_{2} \mathrm{~N}\left(n-\mathrm{C}_{3} \mathrm{H}_{7}\right)$ $\mathrm{SO}_{2} \mathrm{C}_{8} \mathrm{~F}_{17}$ (1) or $\mathrm{CH}_{2}=\mathrm{CH}-\mathrm{OCH}_{2} \mathrm{CF}_{2} \mathrm{CF}_{2} \mathrm{H}(2)$, were polymerized with boron trifluoride etherate $\left(\mathrm{BF}_{3} \mathrm{OEt}_{2}\right)$ and hydrogen iodide/iodine $\left(\mathrm{HI} / \mathrm{I}_{2}\right)$ as initiators at $-15^{\circ} \mathrm{C}$ in methylene chloride or 1,1,2-trichloro-1,2,2-trifluoroethane. With both initiators, vinyl ether 1 was quantitatively polymerized. The polymers obtained with $\mathrm{HI} / \mathrm{I}_{2}$ at conversions below $50 \%$ were soluble, and in this range their number-average molecular weight increased with monomer conversion, indicating the involvement of a long-lived growing species. In contrast, monomer 2 gave insoluble products with $\mathrm{BF}_{3} \mathrm{OEt}_{2}$, and it could not be polymerized with $\mathrm{HI} / \mathrm{I}_{2}$ above $30 \%$ conversion. The $\mathrm{HI} / \mathrm{I}_{2}$-initiated copolymerizations of 1 and $\mathbf{2}$ with 2-chloroethyl vinyl ether (CEVE) showed that the reactivity of these monomers are in the order CEVE $>1>2$. The ${ }^{13} \mathrm{C}$ NMR absorptions of their vinyl $\beta$-carbons shifted downfield in the same order; i.e., the closer the perfluoroalkyl and vinyl groups are located, the lower is the electron density on the vinyl carbon or the lower the reactivity of the monomers. In spite of its relatively low reactivity, vinyl ether 1 yielded not only long-lived homopolymers but also long-lived copolymers with CEVE, when polymerized by $\mathrm{HI} / \mathrm{I}_{2}$.

KEY WORDS Cationic Polymerization / Cationic Copolymerization / Living Polymerization / Perfluoroalkyl Vinyl Ether / Hydrogen IodideIodine Initiator / Boron Trifluoride Etherate /
\end{abstract}

Recently, we have reported ${ }^{1}$ the living cationic polymerization of vinyl ethers with a pendant $p$-substituted phenoxyl group $\left(\mathrm{CH}_{2}=\right.$ $\left.\mathrm{CH}-\mathrm{OCH}_{2} \mathrm{CH}_{2} \mathrm{O}-\mathrm{C}_{6} \mathrm{H}_{4}-\mathrm{X} ; \mathrm{X}=\mathrm{H}, \mathrm{OCH}_{3}, \mathrm{Cl}\right)$ initiated by the hydrogen iodide/iodine $\left(\mathrm{HI} / \mathrm{I}_{2}\right)$ system. $^{2}$ Although the electron-donating phenoxyl pendants were expected to induce chain transfer and other side reactions, these vinyl ethers formed living polymers of a narrow molecular weight distribution (MWD). One of the features of these living processes is that the rate of polymerization clearly increases with increasing electron-donating power of the $p$-substituent.

In order to uncover further the effects of pendant substituents on living cationic polymerization, we employed in this work two perfluoroalkyl vinyl ethers (1 and 2) that differ in structure. Specifically, in monomer 1 the perfluoroalkyl group is well separated from the vinyl ether function by a long spacer (the sulfonamide junction therein exerts no appreciable adverse effects on cationic polymerization), whereas the tetrafluoroethyl moiety of $\mathbf{2}$ is located much closer to the vinyl carbons. To our knowledge, cationic polymerizations of both monomers have not been studied thus far.

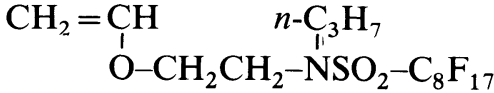

$$
\begin{aligned}
& 1 \\
& \mathrm{CH}_{2}=\underset{1}{\mathrm{CH}} \\
& \mathrm{O}-\mathrm{CH}_{2} \mathrm{CF}_{2} \mathrm{CF}_{2} \mathrm{H} \\
& 2
\end{aligned}
$$


In contrast to the accumulated investigations on radical and anionic polymerizations of fluorine-containing vinyl monomers, ${ }^{3}$ much less is known about their cationic counterparts. It is readily expected that the electronwithdrawing nature of perfluoroalkyl groups may reduce the electron density on the vinyl carbons of monomers and thereby may render their cationic polymerization difficult. Another disadvantage associated with perfluoro monomers is the low solubility of their polymers that often leads to an uncontrollable heterogeneous process.

The electronic insulation of the perfluoroalkyl group from the vinyl function (by at least one methylene unit) in monomers 1 and 2 would give them higher cationic polymerizability; the long hydrocarbon spacer in $\mathbf{2}$ would further benefit this monomer by giving a higher solubility of the polymers in common organic solvents. Noting these structural characteristics, we examined the possibility of living cationic homo- and copolymerizations (with 2-chloroethyl vinyl ether; CEVE) of the two perfluoroalkyl vinyl ethers initiated by the $\mathrm{HI} / \mathrm{I}_{2}$ system.

\section{EXPERIMENTAL}

\section{Materials}

Vinyl ethers 1, 2, and CEVE were supplied by Dainippon Ink Chemical (DIC), Daikin Chemical, and Nisso Maruzen Chemical, respectively. 1 was recrystallized three times from $98 \%$ ethanol and thoroughly dried in vacuo at room temperature. 2 and CEVE were purified by double distillation over calcium hydride under reduced pressure. The gas-chromatographic purities of these monomers were all higher than $99 \%$. Initiators [hydrogen iodide, iodine, and boron trifluoride etherate $\left.\left(\mathrm{BF}_{3} \mathrm{OEt}_{2}\right)\right]$ were obtained as reported. ${ }^{2}$ Methylene chloride $\left(\mathrm{CH}_{2} \mathrm{Cl}_{2}\right)$ and 1,1,2-trichloro-1,2,2-trifluoroethane (Freon) (polymerization solvents), as well as tetrahydronaphthalene and carbon tetrachloride (internal standards for gas chromatography), were distilled at least twice over calcium hydride before use. ${ }^{2}$

\section{Procedures}

Polymerization was carried out under dry nitrogen in a baked glass tube equipped with a three-way stopcock. ${ }^{2}$ The monomer conversion was determined from its residual concentration measured by gas chromatography with tetrahydronaphthalene (for 1) or carbon tetrachloride (for 2) as internal standard $(2.5 \mathrm{vol} \%)$. Cationic copolymerizations of 1 and 2 with CEVE were performed similarly. The reactions were terminated with prechilled ammoniacal methanol (for 1) or ethanol (for 2).

The quenched reaction mixtures were poured into a 30-fold excess of methanol to precipitate the product polymers, the heterogeneous mixtures were allowed to stand overnight, and the polymers were recovered by evaporating. By this procedure, the residual monomer 1 cannot be removed from the product polymers, but it does not interfere with subsequent MWD measurement. The MWD, number-average molecular weight $\left(\bar{M}_{n}\right)$, and polydispersity ratio $\left(\bar{M}_{w} / \bar{M}_{n}\right)$ of the polymers were determined by size-exclusion chromatography in chloroform on the basis of a polystyrene calibration as described previously. ${ }^{1,2}$ ${ }^{1} \mathrm{H}$ and ${ }^{13} \mathrm{C}$ NMR spectra were recorded in $\mathrm{CDCl}_{3}$ at room temperature on a JEOL FX90Q spectrometer.

\section{RESULTS AND DISCUSSION}

\section{Polymerization of 1}

Homopolymerization. Cationic polymerizability of this monomer was examined in $\mathrm{CH}_{2} \mathrm{Cl}_{2}$ at $-15^{\circ} \mathrm{C}$ with the use of three cationic initiators $\left(\mathrm{BF}_{3} \mathrm{OEt}_{2}\right.$, iodine, and $\left.\mathrm{HI} / \mathrm{I}_{2}\right)$ (Table I). In all cases the polymerization quantitatively gave polymers. The reaction mixtures stayed homogeneous at conversions below $50 \%$; above which, however, the polymers 
Table I. Cationic polymerization of vinyl ether $\mathbf{1}^{\mathrm{a}}$

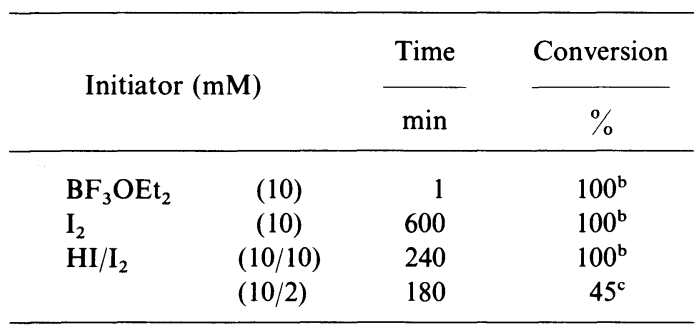

a In $\mathrm{CH}_{2} \mathrm{Cl}_{2}$ at $-15^{\circ} \mathrm{C} ;[\mathrm{M}]_{0}=0.30 \mathrm{M}$.

b Insoluble polymer.

c Soluble polymer; $\bar{M}_{n}=2700$.

precipitated as an oil. The products obtained at $100 \%$ conversion were sticky rubber-like materials that were soluble in Freon and 1,3bis(trifluoromethyl)benzene but insoluble in common organic solvents including chloroform for MWD measurement. Thus, perfluoro monomer 1 turned out to be polymerizable under cationic conditions, although the insolubility of the polymers in chloroform rendered their molecular weights unknown.

More detailed experiments were carried out for the $\mathrm{HI} / \mathrm{I}_{2}$-initiated polymerization in $\mathrm{CH}_{2} \mathrm{Cl}_{2}$ and in Freon at $-15^{\circ} \mathrm{C}$. As summarized in Figure 1, the reactions in both media proceeded smoothly without an induction phase. The overall polymerization rate was greater in Freon than in $\mathrm{CH}_{2} \mathrm{Cl}_{2}$, probably because in the former, the reaction mixture remained homogeneous throughout, whereas in the latter the polymers precipitated at high conversions (see above).

Figure 2 shows the relationship between monomer conversion and the $\bar{M}_{n}$ of the soluble polymers recovered at conversions up to $50 \%$. In this range, the polymer molecular weight increased in direct proportion to conversion, while the MWD stayed narrow $\left(\bar{M}_{w} / \bar{M}_{n} \leq 1.1\right)$. Separate viscosity measurement [in 1,3bis(trifluoromethyl)benzene at $30^{\circ} \mathrm{C}$ ] further showed an increase in polymer molecular weight even at higher conversions. These results indicate the formation of long-lived polymers from 1 in the presence of $\mathrm{HI} / \mathrm{I}_{2}$, though the lack of quantitative molecular weight data

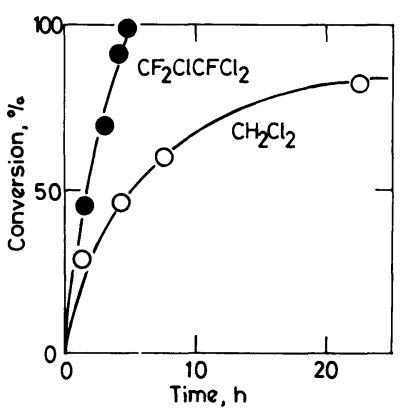

Figure 1. Time-conversion curves for the polymerization of 1 by $\mathrm{HI} / \mathrm{I}_{2}$ at $-15^{\circ} \mathrm{C}$ in $\mathrm{CH}_{2} \mathrm{Cl}_{2}$ and Freon: $[\mathrm{M}]_{0}=0.30 \mathrm{M} ;[\mathrm{HI}]_{0}=10 \mathrm{mM} ;\left[\mathrm{I}_{2}\right]_{0}=2.0 \mathrm{mM}$.

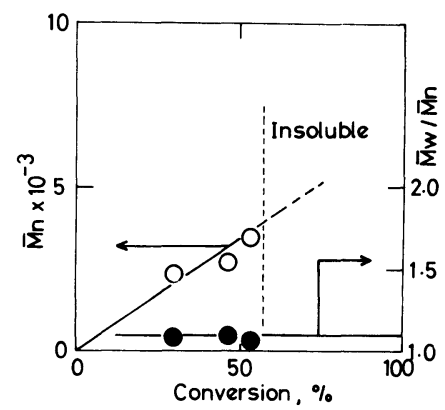

Figure 2. Conversion dependence of the $\bar{M}_{n}$ and $\bar{M}_{w} / \bar{M}_{n}$ of poly(1) obtained by $\mathrm{HI} / \mathrm{I}_{2}$ at $-15^{\circ} \mathrm{C}$ in $\mathrm{CH}_{2} \mathrm{Cl}_{2}:[\mathrm{M}]_{0}=0.30 \mathrm{M} ;[\mathrm{HI}]_{0}=10 \mathrm{mM} ;\left[\mathrm{I}_{2}\right]_{0}=2.0 \mathrm{mM}$.

for high conversions left the conclusion less convincing.

Copolymerization with CEVE. In order to obtain a soluble fluorine-containing poly(vinyl ether) of relatively high molecular weight, 1 was copolymerized with $\mathrm{CEVE}(1: \mathrm{CEVE}=$ $1: 1$ mole ratio in feed) using the $\mathrm{HI} / \mathrm{I}_{2}$ system. Copolymerization study will also give further insight into the reactivity of $\mathbf{1}$ and the living nature of its polymerization; the former will be discussed later in this paper.

Figure 3 shows the time-conversion curves for each comonomer in the copolymerizations at $-15^{\circ} \mathrm{C}$ in $\mathrm{CH}_{2} \mathrm{Cl}_{2}$ and in Freon. In both solvents, CEVE, a less reactive vinyl ether, was consumed more rapidly than $\mathbf{1}$, while the latter was polymerized slowly but smoothly up to $100 \%$ conversion. In contrast to the homopolymerization of 1 , the reaction mixtures 

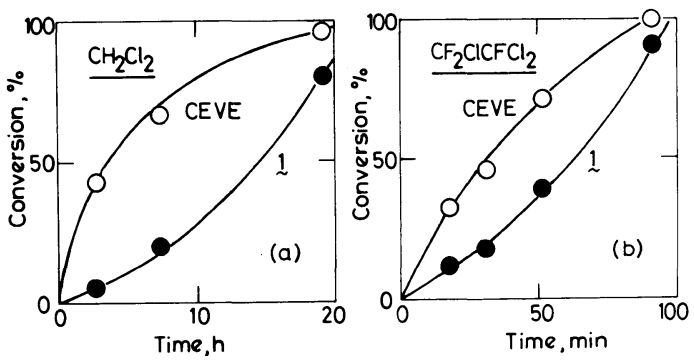

Figure 3. Time-conversion curves for the copolymerization of $1(O)$ with $\operatorname{CEVE}(\bigcirc)$ by $\mathrm{HI} / \mathrm{I}_{2}$ at $-15^{\circ} \mathrm{C}$ : $[1]_{0}=[\mathrm{CEVE}]_{0}=0.30 \mathrm{M}$; (a) in $\mathrm{CH}_{2} \mathrm{Cl}_{2},[\mathrm{HI}]_{0}=10 \mathrm{mM}$, $\left[\mathrm{I}_{2}\right]_{0}=2.0 \mathrm{mM}$; (b) in Freon, $[\mathrm{HI}]_{0}=\left[\mathrm{I}_{2}\right]_{0}=5.0 \mathrm{mM}$.

remained homogeneous throughout the copolymerization even in $\mathrm{CH}_{2} \mathrm{Cl}_{2}$. The isolated polymeric products, including those with a high content of the perfluoro monomer units, were soluble not only in Freon and 1,3bis(trifluoromethyl)benzene but also in common organic solvents (e.g., chloroform) that do not dissolve the homopolymer of the perfluoro vinyl ether.

In addition to such solubility characteristics, the following size-exclusion chromatographic analysis demonstrated the formation of true copolymers between 1 and CEVE. For example, the MWD of the product polymers was narrow and unimodal independent of conversion and the polymerization solvents employed. When eluted in chloroform under refractive-index detection, they gave an eluogram consisting of a single negative peak. Under these analytical conditions, homopolymers of 1 and CEVE exhibit negative and positive signals, respectively, and the refractive index difference with chloroform is much greater for poly(1) than for poly(CEVE). Thus, the single-peaked MWD with negative response indicates that both comonomer units are randomly distributed in a polymer chain over the whole molecular weight range.

Figure 4 shows the $\bar{M}_{n}$ and $\bar{M}_{w} / \bar{M}_{n}$ of the copolymers as a function of the total conversion of the two comonomers. The molec-

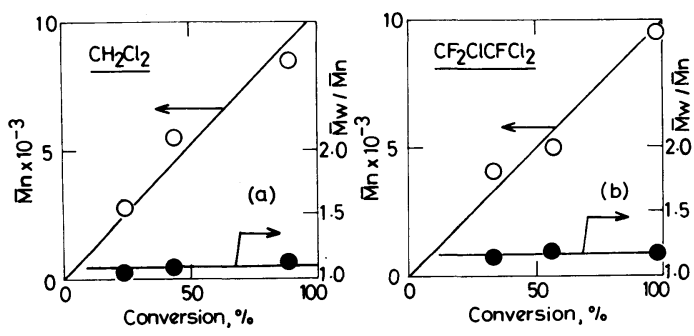

Figure 4. Conversion dependence of the $\bar{M}_{n}$ and $\bar{M}_{w} / \bar{M}_{n}$ of the copolymers of 1 with CEVE obtained by $\mathrm{HI} / \mathrm{I}_{2}$ at $-15^{\circ} \mathrm{C}:[1]_{0}=[\mathrm{CEVE}]_{0}=0.30 \mathrm{M}$; (a) in $\mathrm{CH}_{2} \mathrm{Cl}_{2}$, $[\mathrm{HI}]_{0}=10 \mathrm{mM},\left[\mathrm{I}_{2}\right]_{0}=2.0 \mathrm{mM}$; (b) in Freon, $[\mathrm{HI}]_{0}=$ $\left[\mathrm{I}_{2}\right]_{0}=5.0 \mathrm{mM}$.

Table II. Cationic polymerization of vinyl ether $2^{\text {a }}$

\begin{tabular}{lccccc}
\hline \multirow{2}{*}{ Initiator $(\mathrm{mM})$} & \multicolumn{2}{c}{ Time } & & \multicolumn{2}{c}{ Conversion/\% } \\
\cline { 5 - 6 } & & $\mathrm{h}$ & & $\mathrm{CH}_{2} \mathrm{Cl}_{2}$ & Freon \\
\hline $\mathrm{BF}_{3} \mathrm{OEt}_{2}$ & $(10)$ & 24 & $67^{\mathrm{b}}$ & $88^{\mathrm{b}}$ \\
$\mathrm{HI} / \mathrm{I}_{2}$ & $(10 / 10)$ & 24 & & 11 & 27 \\
\hline
\end{tabular}

a At $-15^{\circ} \mathrm{C} ;[\mathrm{M}]_{0}=0.30 \mathrm{M}$.

b Insoluble polymer.

ular weight of the copolymers obtained in both $\mathrm{CH}_{2} \mathrm{Cl}_{2}$ and Freon were directly proportional to the conversion, and the polymer MWD remained narrow $\left(\bar{M}_{w} / \bar{M}_{n}<1.2\right)$ during the copolymerization. Accordingly, perfluoro monomer 1 forms a living copolymer with CEVE when polymerized by the $\mathrm{HI} / \mathrm{I}_{2}$ system.

\section{Polymerization of $\mathbf{2}$}

Homopolymerization. Vinyl ether $\mathbf{2}$, in which a perfluoroalkyl group is much closer to the vinyl moiety than in monomer 1 , was treated with $\mathrm{BF}_{3} \mathrm{OEt}_{2}$ and $\mathrm{HI} / \mathrm{I}_{2}$ at $-15^{\circ} \mathrm{C}$ in $\mathrm{CH}_{2} \mathrm{Cl}_{2}$ or in Freon to examine its cationic polymerizability (Table II). The polymerization of 2 with $\mathrm{BF}_{3} \mathrm{OEt}_{2}$ turned out to be much slower than that of 1 , requiring $24 \mathrm{~h}$ to reach $c a .70-90 \%$ conversion, in which period polymers precipitated in the reaction mixtures. $\mathrm{HI} / \mathrm{I}_{2}$ led to an even slower consumption of 2 . Thus the cationic polymerizability of $\mathbf{2}$ is rather low.

Copolymerization with CEVE. Copolymer- 
Table III. Relative polymerization rates ${ }^{\mathrm{a}}$ and ${ }^{13} \mathrm{C}$ NMR chemical shifts of vinyl ethers 1 and 2

\begin{tabular}{|c|c|c|c|c|}
\hline \multirow{2}{*}{ Monomer } & & \multirow{2}{*}{ Relative rate } & \multicolumn{2}{|c|}{${ }^{13} \mathrm{C}$ NMR } \\
\hline & & & $\beta$ & $\alpha$ \\
\hline $\begin{aligned} \mathrm{CH}_{2}= & \underset{1}{\mathrm{C}} \mathrm{H} \\
& \mathrm{O}-\mathrm{CH}_{2} \mathrm{CF}_{2} \mathrm{CF}_{2} \mathrm{H}\end{aligned}$ & (2) & $\sim 0.01$ & 88.7 & 150.5 \\
\hline $\begin{aligned} \mathrm{CH}_{2}= & \underset{1}{\mathrm{CH}} \stackrel{n-\mathrm{C}_{3} \mathrm{H}_{7}}{ } \\
& \mathrm{O}-\mathrm{CH}_{2} \mathrm{CH}_{2} \mathrm{NSO}_{2}-\mathrm{C}_{8} \mathrm{~F}_{17}\end{aligned}$ & (1) & $\sim 0.1$ & 87.8 & 150.9 \\
\hline $\begin{aligned} \mathrm{CH}_{2}= & \underset{1}{\mathrm{CH}} \\
& \mathrm{O}-\mathrm{CH}_{2} \mathrm{CH}_{2} \mathrm{Cl}\end{aligned}$ & (CEVE) & 1 & 87.5 & 151.3 \\
\hline
\end{tabular}

${ }^{\text {a }}$ Estimated, relative to CEVE, from the slope of the first-order plot for monomer consumption in the copolymerization with $\mathrm{CEVE}$ in $\mathrm{CH}_{2} \mathrm{Cl}_{2}$ at $-15^{\circ} \mathrm{C}$; [comonomer $]_{0}=0.30 \mathrm{M}$ each, $[\mathrm{HI}]_{0}=10 \mathrm{mM},\left[\mathrm{I}_{2}\right]_{0}=2.0 \mathrm{mM}$.
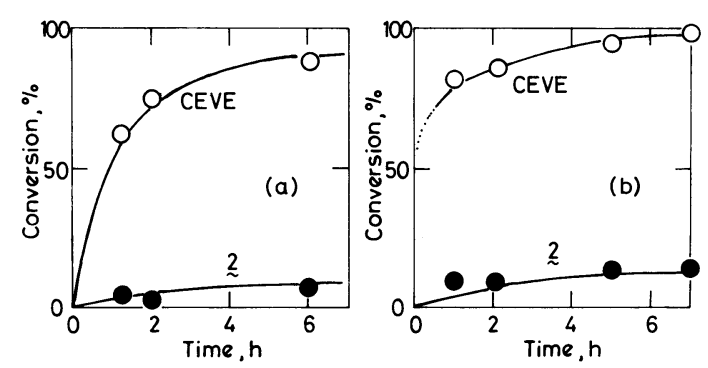

Figure 5. Time-conversion curves for the copolymerization of $2(O)$ with $\operatorname{CEVE}(\bigcirc)$ at $-15^{\circ} \mathrm{C}$ and $[2]_{0}=$ $[\mathrm{CEVE}]_{0}=0.30 \mathrm{M}$. Initiator: (a) $\mathrm{HI} / \mathrm{I}_{2}, 10 / 2.0 \mathrm{mM}$; (b) $\mathrm{BF}_{3} \mathrm{OEt}_{2}, 2.0 \mathrm{mM}$.

ization of 2 with CEVE was carried out in $\mathrm{CH}_{2} \mathrm{Cl}_{2}$ at $-15^{\circ} \mathrm{C}$ using $\mathrm{BF}_{3} \mathrm{OEt}_{2}$ and $\mathrm{HI} / \mathrm{I}_{2}$ as initiators (Figure 5). In contrast to the rapid polymerization of CEVE with both initiators, the conversion of $\mathbf{2}$ did not exceed $20 \%$. The polymers were soluble in common organic solvents such as $\mathrm{CH}_{2} \mathrm{Cl}_{2}$ and chloroform where the homopolymer of $\mathbf{2}$ is insoluble, and they were shown by ${ }^{1} \mathrm{H}$ NMR spectroscopy to contain the repeat units of 2 . Although the content of $\mathbf{2}$ is low, true copolymers were obtained from CEVE and 2.

The molecular weight of the products was similar to those of homopoly(CEVE) prepared under the same conditions, but the MWD bacame broader $\left.\left(\bar{M}_{w} / \bar{M}_{n}\right)=1.2-1.3\right)$ when 2 was incorporated into the copolymers at later stages of the copolymerization. These results again show that $\mathbf{2}$, though cationically polymerizable, has very low polymerization reactivity and is incapable of producing living or long-lived (co)polymers.

\section{Reactivity of Perfluoro Vinyl Ethers}

Table III compares the polymerization reactivities of the two fluorine-containing vinyl ethers and CEVE. Relative reactivity was evaluated from the initial slope of the firstorder plot for monomer consumption in the copolymerizations with CEVE. Monomers 1 and 2 were less reactive than CEVE, and their reactivity decreased in the order $(\mathrm{CEVE}>\mathbf{1}>2)$ by a factor proportional to the proximity of the perfluoroalkyl pendant to the vinyl ether moiety.

Table III also shows the ${ }^{13} \mathrm{C}$ NMR chemical shifts of the vinyl groups in the three monomers, which reflect the electron density on a carbon atom. ${ }^{4}$ Relative to CEVE, the $\beta$-vinyl carbons of the perfluoro monomers resonated downfield, only slightly with 1 but considerably with 2 . Namely, the closer the pendant perfluoroalkyl group is to the vinyl moiety, the lower is the electron density on the $\beta$-carbon. Also, the extent of this decrease (or the downfield shift of the $\beta$-carbon signal) is apparently correlated to the reactivity order of the three monomers. 
W. O. Choi. M. Sawamoto, and T. Higashimura

\section{REFERENCES}

1. W. O. Choi, M. Sawamoto, and T. Higashimura, Polym. J., 19, 889 (1987).

2. M. Miyamoto, M. Sawamoto, and T. Higashimura, Macromolecules, 17, 265, 2228 (1984).

3. For reviews, see, for example, (a) L. A. Wall, Ed.,
"Fluoropolymers," Wiley-Interscience, New York (1972); (b) T. Narita, Kagaku Kogyo (Chem. Ind.), 38, 153 (1987).

4. (a) T. Higashimura, S. Okamura, I. Morishima, and T. Yonezawa, J. Polym. Sci., B, 7, 23 (1969); (b) H. Yuki, K. Hatada, K. Nagata, and T. Emura, Polym. J., 1, 269 (1970). 